\title{
Alkali-Active Sand Slate Powder for Use as Mineral Admixture in Mass Hydraulic Concrete: Technical and Economic Analysis
}

\author{
Xia Chen (iD, Xian Zhou (iD, Ziling Peng, and Jiazheng Li $(\mathbb{D}$ \\ Department of Materials and Structure, Changjiang River Scientific Research Institute, CRWRC, Wuhan 430010, China \\ Correspondence should be addressed to Xia Chen; chenxia1017@126.com
}

Received 19 August 2021; Revised 10 November 2021; Accepted 12 November 2021; Published 29 November 2021

Academic Editor: Robert Černý

Copyright (C) 2021 Xia Chen et al. This is an open access article distributed under the Creative Commons Attribution License, which permits unrestricted use, distribution, and reproduction in any medium, provided the original work is properly cited.

\begin{abstract}
This work has launched a comprehensive investigation on the macro performance and micro structure of mass concrete produced with alkali-active sand slate powder (ASSP) for use as the mineral admixture and a thorough analysis on its technical and economic effects is also conducted. Results indicated ternary blend with hybrid of 5-8 wt.\% silica fume (SF) and 15-20 wt.\% ASSP has the optimal compressive and flexural strength. ASSP particle participates in hydration, accelerates hydration of cement clinker within 8.5 hours, and reduces the autogenous strain of pastes by $164 \times 10^{-6}$ in case of dosage less than $25 \%$ by mass. Improvement in the mechanical and deformation properties of concrete produced with the hybrid of SF and ASSP is attributed to better particles gradation, compactness enhancement, and transformation in products of hydration. On the whole, it provides another new approach for use of alkali-active rock after second processing as mineral admixture in hydraulic concrete in terms of good performance and economic effects.
\end{abstract}

\section{Introduction}

Mineral admixture is of great importance for improving the performance of fresh and hardened hydraulic concrete and saving cost. Great success has been achieved in the prevailing use of fly ash (FA), silica fume (SF), and blast furnace slag $[1,2]$ as mineral admixture, especially when aggregates are alkali-active [3-5]. The Danjiangkou hydropower station, which is a Water Source of South-toNorth Water Diversion project, used blast furnace slag as mineral admixture because flint was detected in the aggregates. Both Xiaolangdi and Jinping I hydropower stations [6] used FA and low-alkali cement as admixture to batch concrete to ensure dam safety. The Jinping I hydropower station, which has a dam height of $305 \mathrm{~m}$, used fine marble and coarse sandstone aggregates to batch dam concrete in which the coarse sandstone aggregate was determined as alkali-active silica, and FA of good quality and low-alkali cement were used to prevent it from AAR risk. Yet, the incorporation of siliceous FA has negative effects due to the lowering of strength parameters of composites in early stages of curing. In order to overcome such shortcomings, Nanometric C-S-H Seeds are introduced [7], which could accelerate the binding process and neutralize the negative influence of the used industrial waste on the structure of the cement matrix in the early stages of its curing [8].

Some attempts have also been made for the utilization of limestone and tuff powders as mineral admixtures. The limestone powder obtained by grinding limestone parent rock is widely acknowledged as a low-activity or inert material, but it has positive effect on the early hydration acceleration of aluminum- and silicon-phase minerals in the cement clinker, which contributes to its filling, nucleation, dilution, and chemical effects (Ramon et al. [9]; Liu and Yan [10]; Wang et al. [11]). Limestone powder was also reported to be effective to inhibit AAR [12]; that is, the expansion ratios at 14 days and 28 days of mortar are both less than $0.10 \%$ when more than $45 \mathrm{wt} . \%$ of limestone powder, 15 wt.\% of limestone powder and 30 wt.\% of FA or the combination of $25 \mathrm{wt} . \%$ of limestone powder and $25 \mathrm{wt} . \%$ of FA are added, respectively. The mechanical property and durability of cement-based materials incorporated with limestone powder have also been widely investigated 
[13-15]. Zeolite-type tuff powder has gained recognition as pozzolanic active material [16-18] and has been recommended for manufacturing environment-friendly composite cement. The morphological and microaggregate effects of tuff powder $[19,20]$ are reportedly very active at the early stage of hydration when used as a mineral admixture for concrete.

Nevertheless, no report has been made on fine powders obtained by grinding alkali-active aggregate and used as mineral admixture in concrete. In this paper, the aim is to investigate the feasibility of alkali-active rock after second processing for use as mineral admixture for the first time in mass hydraulic concrete. Alkali-active silica sand slate, which is regarded as a harmful aggregate and should be excavated, is widely distributed along the Yalong River basin where mass-scale hydropower station construction is underway, and the use of local excavated harmful sand slate must be maximized to satisfy the large demand for aggregates and mineral admixture for use in constructing dam concrete. Alkali silica sand slate is primarily composed of $\mathrm{SiO}_{2}$ and $\mathrm{Al}_{2} \mathrm{O}_{3}$ and thus becomes a latent cementitious material after being ground into fine particles. He et al. [20] explored the potential use of sandstone powder as a mineral additive in concrete and confirmed the effectiveness of adding sandstone powder for ASR inhibition. Here, the effect of alkali-active sand slate powder (ASSP) on the macro performance and micro structure of binary and ternary blends is investigated to explore the feasibility of using ASSP as a mineral admixture for the Lianghekou hydropower dam concrete to ease the great tension between the supply and demand of conventional mineral additives, such as FA and blast furnace slag, which are difficult to acquire because of transportation and cost issues.

\section{Materials and Methods}

2.1. Raw Materials. Medium heated Portland cement of grade 42.5 (P.MH 42.5), which has a specific surface area of $290 \mathrm{~m}^{2} / \mathrm{kg}$ and is produced by Esheng Cement Co., Ltd., is used for testing. FA (with a specific surface area of $360 \mathrm{~m}^{2} / \mathrm{kg}$ and a water consistency rate of 101\%) and SF, which are, respectively, produced by Sichuan Taofeng Trade Co., Ltd., and Sichuan Langtian Resource Comprehensive Utilization Co., Ltd., are both used for testing. The chemical components of these three cementitious materials are listed in Table 1 , in which $\mathrm{R}_{2} \mathrm{O}$ is equivalent to the sum of $0.658 \mathrm{~K}_{2} \mathrm{O}$ and $\mathrm{Na}_{2} \mathrm{O}$, and the comparison of the particles distribution of ASSP and SF used for tests is presented in Figures 1 and 2. Clearly, SF has finer particles than ASSP and exhibits aggravated particle agglomeration.

The AAR detection results on an alkali-active sand slate parent rock conducted by accelerated mortar bar test according to ASTM C 1260 are listed in Table 2. Apparently, the parent rock is potentially alkali-active silica with 14 days of expansion reaching $0.229 \%$, that is, greater than $0.10 \%$, which is the threshold for determining the ASR risk. The sand slate parent rock was crushed with a Barmac crusher into less than $10 \mathrm{~mm}$ particles, which were subsequently placed in a vertical mill (RM2200) for finer grinding. For use as a mineral admixture, ASSP with a specific surface area of $640 \mathrm{~m}^{2} / \mathrm{kg}$ were obtained by grinding the above-mentioned fine sand slate aggregate sized less than $4.75 \mathrm{~mm}$ with ball mill for another 50 minutes.

\subsection{Experimental Methods}

\subsubsection{Mechanical Properties}

(1) Compressive and Flexural Strength. Prism specimens with $40 \mathrm{~mm} \times 40 \mathrm{~mm} \times 160 \mathrm{~mm}$ dimensions were prepared with water/binder ratio and sand/binder ratio of 0.50 and 3.0, respectively, and water, binder, and sand were successively added and batched using a planetary type mortar mixer. The specimens were cured in moisture for 24 hours and then demolded and cured in water until the strength test. At the testing age, the specimens were taken out of the water, and the flexural strength test was conducted first. Then, the compressive strength test was performed on each section after the appearance of fracture.

For the mix proportion of the binary blends of P.MH 42.5 and ASSP, the replacement ratio of ASSP by mass of total cementitious materials is $0,15 \%, 25 \%, 35 \%, 45 \%$, and $55 \%$, by mass, and the corresponding samples are coded as A0, A1, A2, A3, A4, and A5, respectively.

For the mix proportion of the ternary blends of P.MH 42.5 , FA, and ASSP, a coupled addition of $10 \%$ of FA and $15 \%$ of ASSP by mass are incorporated and sample is coded as AF1.

For the mix proportion of the ternary blends of $\mathrm{P} \cdot \mathrm{MH} 42.5$, $\mathrm{SF}$, and ASSP, the replacement ratio of SF is 3\%, 5\%, and $8 \%$ by mass, respectively, and for each group, a coupled addition of $15 \%, 20 \%$, and $25 \%$ of ASSP by mass is together incorporated. Samples are coded as S1 to S8 as illustrated in Table 3.

(2) Autogenous Strain. The autogenous strain of the binary blend of samples coded A0 to A5 was measured using the YC-BWS Bellows autogenous-strain measuring instrument in accordance with the ASTM C1698-19 Standard Test Method for Autogenous Strain of Cement Paste and Mortar. The samples were prepared with the water/binder ratio of 0.28 . The well-mixed mixture was grouted in sylphon seal bellows sized $\Phi 29 \mathrm{~mm} \times 430 \mathrm{~mm}$ with a measurement accuracy of $1 \mu \mathrm{m}$. Taking the final setting as the zero point, data were collected every half an hour for 12 hours, every hour for 24 hours, and then every 2 hours after 24 hours.

2.2.2. Heat of Hydration. The SETARAM type C80 isothermal calorimetry measurements of the hydration heat of samples coded A0, A1, and S8 were taken. The blends were premixed. Then, $500 \mathrm{mg}$ of mixed sample was weighed for the experiment. The water/mixed sample ratio for the test was 1.0, analytical reagent $\mathrm{SiO}_{2}$ was used for reference, and the testing temperature was controlled at $30.0 \pm 0.1^{\circ} \mathrm{C}$.

2.2.3. Micro Analysis. Samples coded A0, A2, AF1, and S5 were separately mixed with water at the water/binder ratio of 
TABLE 1: Chemical components of cement, FA, and SF (\%).

\begin{tabular}{lcccccccc}
\hline Materials & $\mathrm{CaO}$ & $\mathrm{SiO}_{2}$ & $\mathrm{Al}_{2} \mathrm{O}_{3}$ & $\mathrm{Fe}_{2} \mathrm{O}_{3}$ & $\mathrm{MgO}$ & $\mathrm{SO}_{3}$ & $\mathrm{R}_{2} \mathrm{O}$ & Loss on ignition \\
\hline Cement & 59.3 & 22.8 & 3.1 & 4.8 & 4.7 & 2.2 & 0.3 & 1.4 \\
FA & 1.8 & 53.0 & 22.9 & 10.2 & 3.3 & 1.0 & 1.5 & 5.6 \\
SF & - & 88.4 & - & - & - & 0.7 & 0.4 & 3.2 \\
ASSP & 2.2 & 64.2 & 14.5 & 5.7 & 4.5 & 0.2 & 3.1 & 3.0 \\
\hline
\end{tabular}

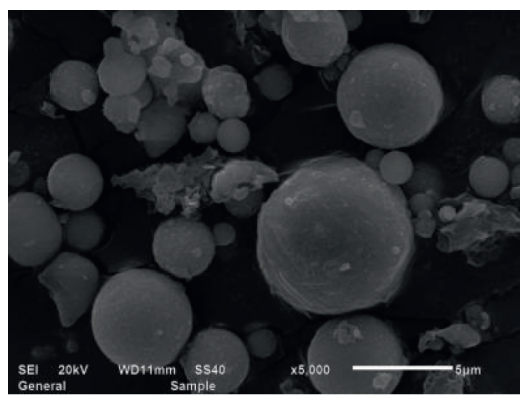

(a)

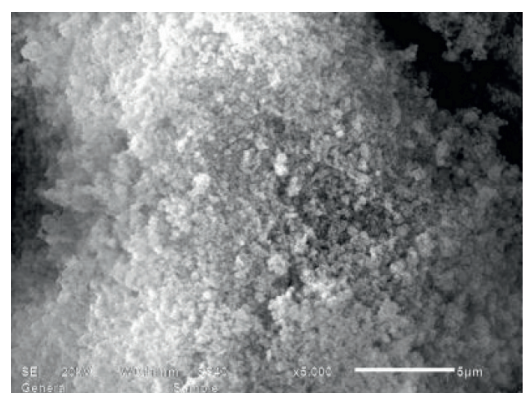

(b)

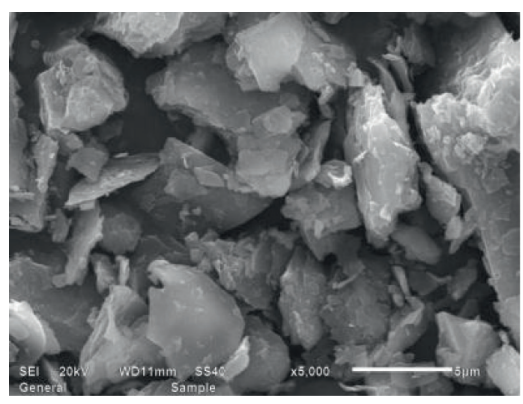

(c)

Figure 1: SEM patterns of FA, SF, and ASSP particles morphology ( $\times 5000$ times). (a) FA. (b) SF. (c) ASSP.

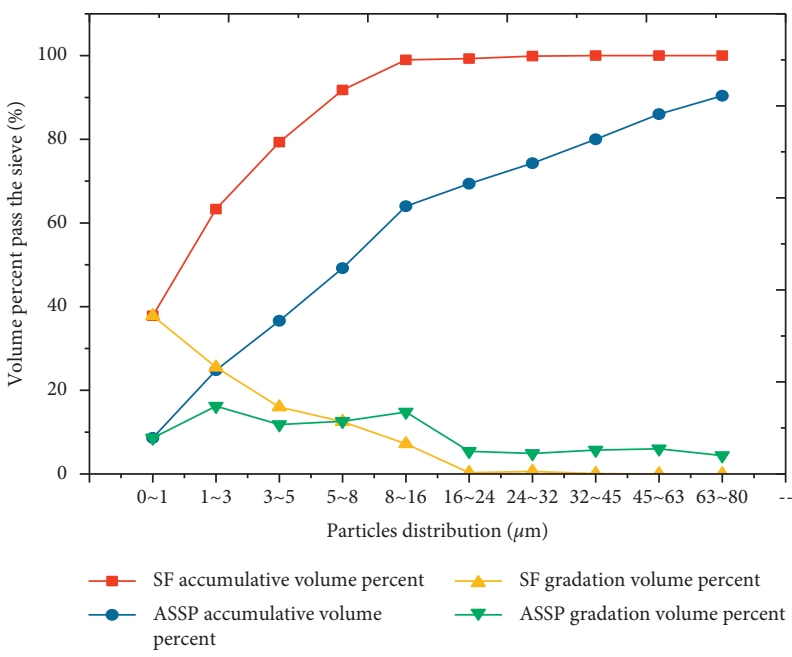

FIgURe 2: Particles distribution of ASSP by laser analyzer.

0.50. Samples with $40 \mathrm{~mm} \times 40 \mathrm{~mm} \times 40 \mathrm{~mm}$ dimensions were prepared and cured in moisture for 24 hours and then demolded and cured in water until the test age. At the test age, the samples were taken out from the water and crushed. Then, the center of the broken sample was taken out and soaked in absolute ethanol to prevent further hydration. The prepared samples were dried in an oven at $60^{\circ} \mathrm{C}$ for 24 hours and then prepared for the following micro structure tests.

(1) Scanning Electron Microscope/Energy-Dispersive Spectrometer (SEM/EDS). The morphologies of the hydration products of samples coded A2, AF1, and S5 were observed by field emission scanning electron microscopy using the Zeiss Ultra Plus.

(2) X-Ray Diffraction (XRD). The products of hydration were observed using the D8 advance X-ray diffractometer produced by AXS, Brooke, Germany. The scanning range $2 \theta$ of the instrument is from 10 to $80^{\circ}$, and the goniometer radius is greater than or equal to $200 \mathrm{~mm}$.

(3) Differential Thermal Analysis and Thermogravimetric analysis (DTA-TG). Thermogravimetric analysis was performed on the binary and ternary blends using SDT Q600. The heating interval was from 60 to $1000^{\circ} \mathrm{C}$ and the heating rate was $10^{\circ} \mathrm{C} / \mathrm{min}$. The corresponding temperature ranges of endothermic decomposition of $\mathrm{Ca}(\mathrm{OH})_{2}$ and $\mathrm{CaCO}_{3}$ on the TG curve were $440-540^{\circ} \mathrm{C}$ and $700-900^{\circ} \mathrm{C}$, respectively. According to the test results, the amount of $\mathrm{Ca}(\mathrm{OH})_{2}$ and chemical combined water in the gel could be calculated.

(4) Mercury Intrusion Porosimetry (MIP). The pore structure evolution of the binary and ternary blends was measured by 
TABLE 2: AMBT detection results of sand slate parent rock.

\begin{tabular}{lcccrr}
\hline Testing age & $3 \mathrm{~d}$ & $7 \mathrm{~d}$ & $14 \mathrm{~d}$ & $21 \mathrm{~d}$ & $28 \mathrm{~d}$ \\
\hline Expansion rate of mortar (\%) & 0.063 & 0.161 & $\mathbf{0 . 2 2 9}$ & 0.317 & 0.359 \\
\hline
\end{tabular}

TABLE 3: Samples coding and mix proportion of binary and ternary blends for macro and micro tests.

\begin{tabular}{llcll}
\hline Sample coding & FA & ASSP & ASSP + FA & SF-ASSP \\
\hline F0-F5 & $0,5 \%, 25 \%, 35 \%, 45 \%, 55 \%$ & - & & - \\
A1-A5 & - & $0,15 \%, 25 \%, 35 \%, 45 \%, 55 \%$ & & \\
AF1 & - & - & $10 \%$ FA + 15\% ASSP & $3 \%$ SF + (15\%, 20\%, 25\%) ASSP \\
S1-S3 & - & - & $5 \%$ SF + (15\%, 20\%, 25\%) ASSP \\
S4-S6 & - & - & $8 \%$ SF + (15\%, 20\%, 25\%) ASSP \\
S7-S9 & - & - & & - \\
\hline
\end{tabular}

Mercury intrusion porosimetry (MIP), and the low and high pressure values of Mercury intrusion ranged from 0.007 to $0.207 \mathrm{MPa}$ and from 0.207 to $379.225 \mathrm{MPa}$, respectively.

\section{Results and Discussions}

\subsection{Mechanical and Deformation Properties}

3.1.1. Compressive Strength. The compressive strength testing results of the binary and ternary blend mortars are illustrated in Figure 3. The compressive strength of binary blend mortar of P.MH 42.5 and ASSP presents a decreasing trend with the increasing amounts of ASSP from 15\% to $55 \%$, as well as a decreasing trend from 18.6 to $11.1 \mathrm{MPa}$ on the 7 th day and from 43.3 to $13.9 \mathrm{MPa}$ on the 28th day. The compressive strength of the binary blend mortar of $\mathrm{P} \cdot \mathrm{MH}$ 42.5 and ASSP is equal to that of the binary blend mortar of $\mathrm{P} \cdot \mathrm{MH} 42.5$ and FA on the 28th day when the replacement is less than $45 \%$ but exhibits greater growth when the testing age is extended from the 28 th day to the 90 th day, $172 \%$ and $125 \%$ on average to be specific, respectively.

The compressive strength of the ternary blend mortar of $\mathrm{P} \cdot \mathrm{MH}$ 42.5, FA, and ASSP is different from those of the binary blend mortars with ASSP and FA incorporated. The compressive strength of the ternary blend mortar of P.MH 42.5, SF, and ASSP exhibits significant growth compared with those of the other two types of binary blend mortars, and the ternary blend mortars with SF addition ranging from 5 to $8 \mathrm{wt} . \%$ and ASSP replacement ranging from 15 to $20 \mathrm{wt}$.\% have the highest compressive strength. The hybrid ASSP with SF ranging from 5 to 8 wt.\% demonstrates an effective way of enhancing the strength, which is consistent with a previous study [21], confirming the feasibility of using hybrid ASSP and SF as a partial replacement of cement to improve the mechanical performance of concrete.

3.1.2. Flexural Strength. The flexural strength testing results of the binary and ternary blend mortars are illustrated in Figure 4. Apparently, the flexural strength of the binary blend of samples coded A0 to A5 also presents a decreasing trend with the amount of ASSP increasing from 15 to 55 wt.\%. The flexural strength of samples coded A0 to A5 exhibits significant growth from the 7 th day to the 28th day, which is consistent with the compressive strength development trends, but the flexural strength of samples coded F0 to F5 displays greater increase from 28 days to 180 days, suggesting the greater contribution of FA to the latter strength growth of the mortar because of its higher pozzolanic activity than ASSP. The incorporation of SF has a significant enhancement effect on flexural strength, and the ternary blends of samples coded S4 and S5 and S7 and S8 produce optimal flexural strength as shown in Figure 4(d).

The flexural strength to compressive strength ratios of the ternary blend of sample coded AF1 lie between those of the single FA and ASSP binary blends when the test age is within 7 days; when the test age extends to the 90th day and the 180th day, the binary blend mortar of P.MH 42.5 and ASSP had a higher ratio of flexural strength to compressive strength, indicating that adding the appropriate amount of ASSP has a positive effect on mortar ductility improvement at the latter stage.

3.1.3. Autogenous Strain. The autogenous strain testing results of samples coded A0 to A5 are shown in Figure 5. Clearly, the autogenous strains of samples increase significantly within 8.5 hours and then exhibit moderate growth up to 62 hours. When the addition dosage of ASSP ranges from 15 to $55 \mathrm{wt} . \%$, the autogenous strain of the binary blends ranges from $631 \times 10^{-6}$ to $1024 \times 10^{-6}$ within 8.5 hours and reaches $655 \times 10^{-6}$ and $1210 \times 10^{-6}$ in 62 hours, respectively.

Within 8.5 hours, the cement paste has the lowest autogenous strain. Subsequently, the binary blend paste with the ASSP ranging from 15 to 25 wt.\% achieves a lower autogenous strain than that of the cement paste, and the binary blend of samples coded A3 to A5 achieves larger autogenous strain than that of the cement paste. Specifically, from 8.5 hours to 62 hours, the autogenous strain of the binary blend paste decreases with the increase of the ASSP amount from 0 to 25 wt.\% and increases with the ASSP increase from 35 to 55 wt.\%.

Thus, adding ASSP would accelerate the hydration of the cement clinker within 8.5 hours due to the uniformly distributed fine particles of ASSP acting as dispersion activation nucleation points, increasing the autogenous strain. In general, the majority of the cement particles ranged between 10 and $60 \mu \mathrm{m}$, and $38.1 \%$ of the ASSP were below $5 \mu \mathrm{m}$ and $72.8 \%$ were below $24 \mu \mathrm{m}$, as illustrated in 


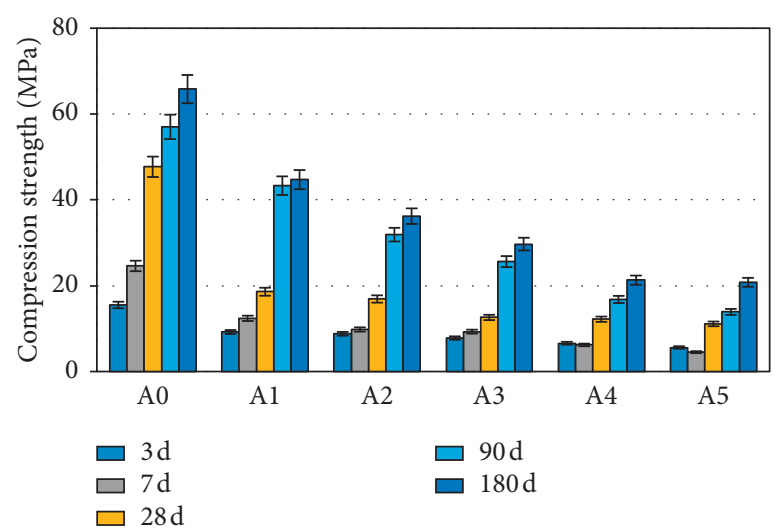

(a)

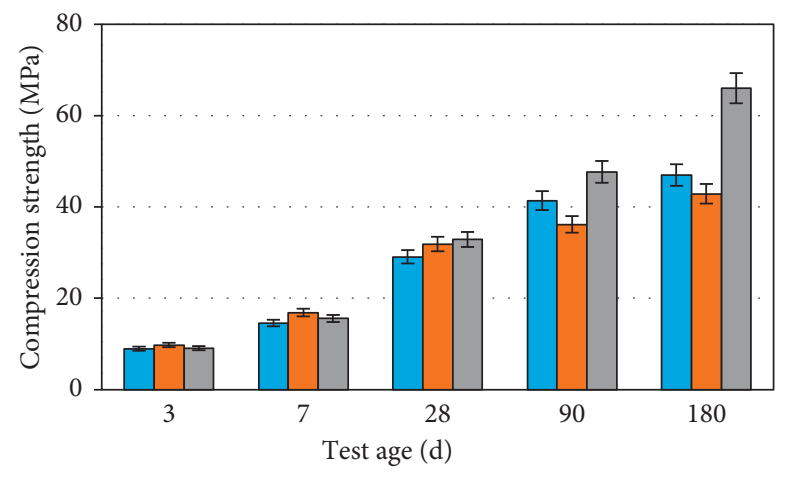

$$
\begin{aligned}
& \square \text { AF1 } \\
& \square \text { A2 } \\
& \square \text { F2 }
\end{aligned}
$$

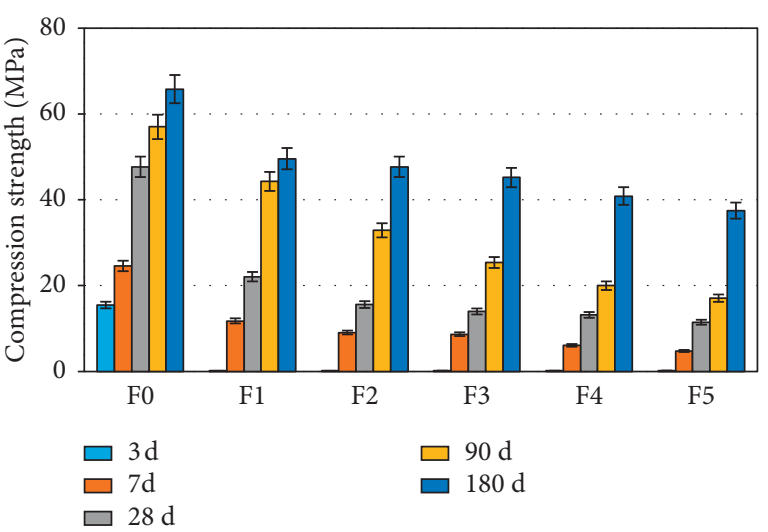

(b)

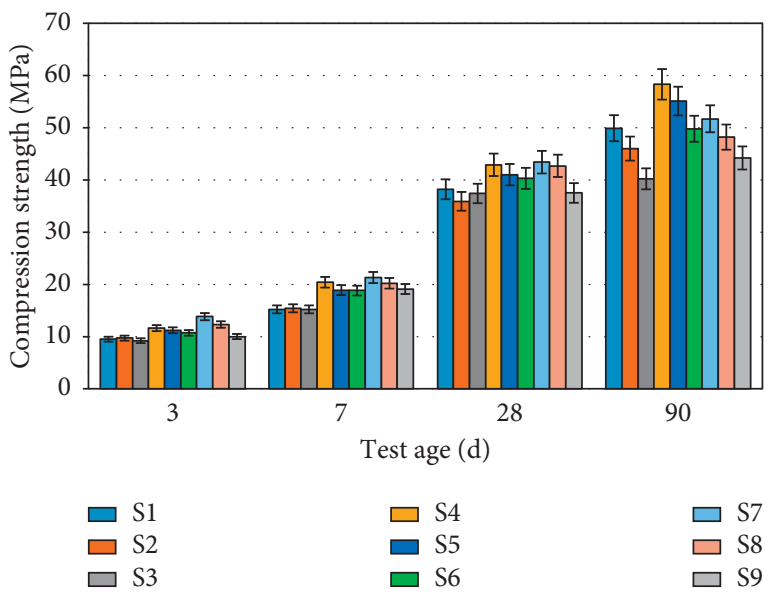

(d)

Figure 3: The compressive strength of the binary and ternary blends mortars. (a) The binary blends of P.MH 42.5 and ASSP, (b) the binary blends of P.MH 42.5 and FA, (c) the binary blends mortar comparison, and (d) the ternary blends mortar of P.MH 42.5, SF, and ASSP.

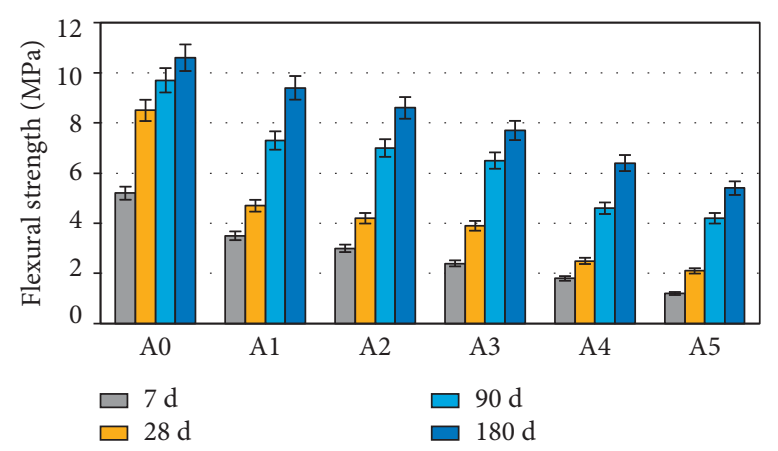

(a)

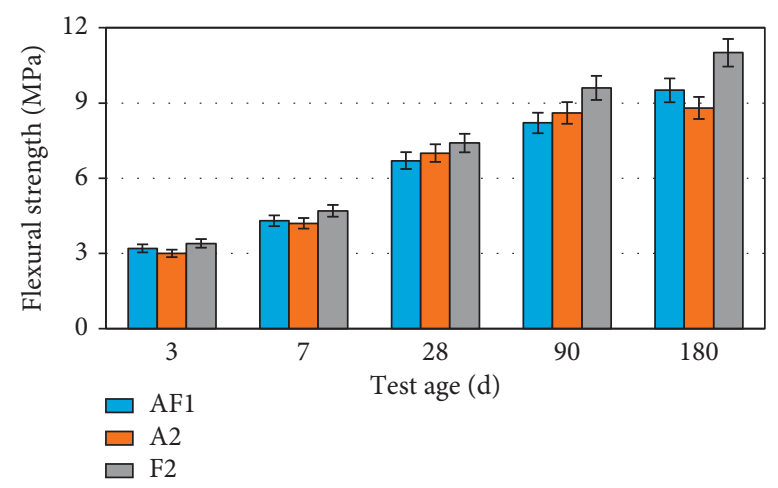

(b)

FIgURE 4: Continued. 


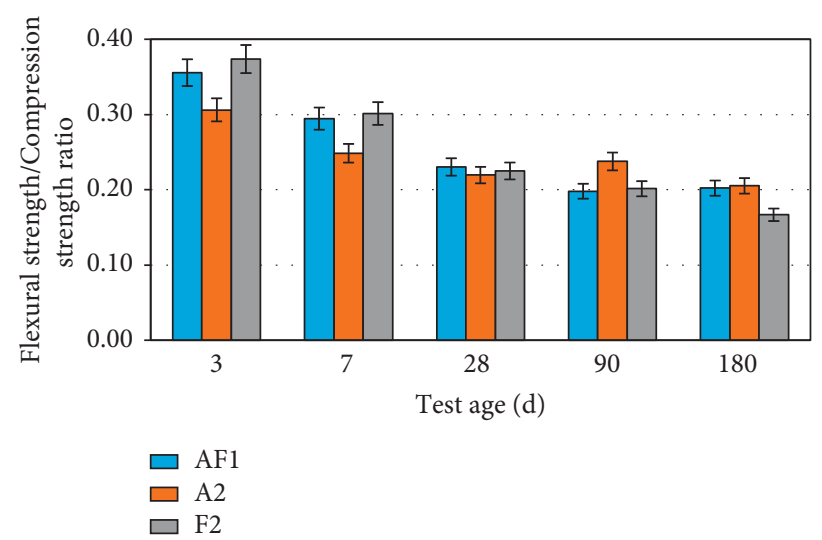

(c)

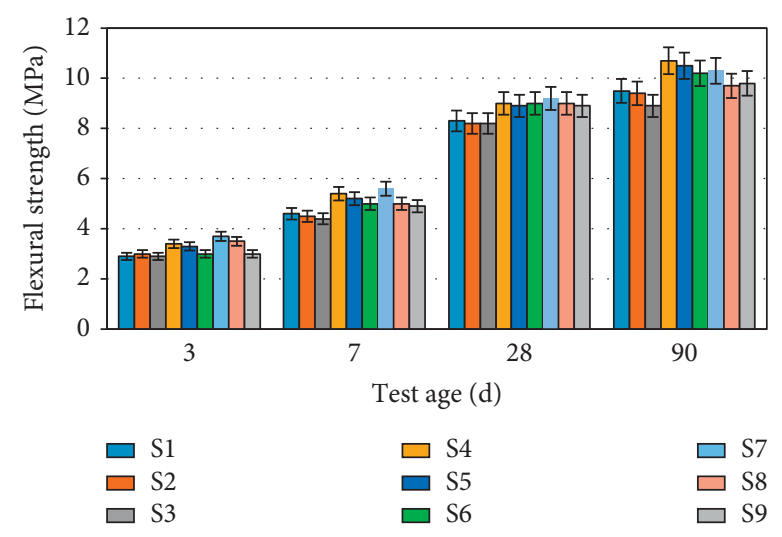

(d)

FIGURE 4: The flexural strength of binary and ternary blends mortar. (a) ASSP binary blends, (b) ASSP and FA binary blends comparison, (c) flexural/compressive strength ratio, and (d) SF and ASSP ternary blends.

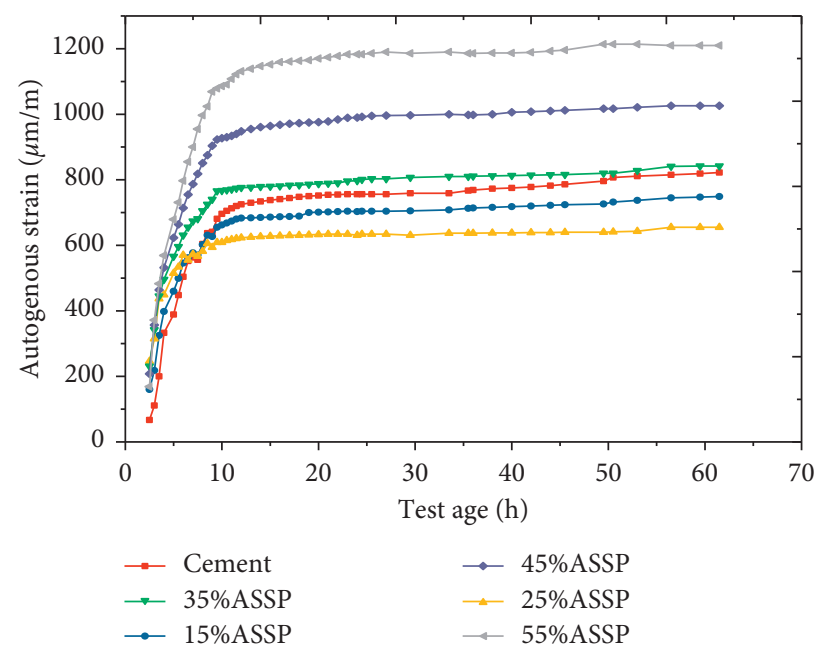

FIgURE 5: Autogenous strain of ASSP binary blends.

Figure 6. When ASSP below 25\% was blended with cement, the particle size distribution and gradation between powders improved and are also favorable for mitigating the autogenous strain. Notably, according to $\mathrm{Ma}$ et al. [22], the selection of zero point has a significant influence on autogenous shrinkage, and the internal capillary pressure in the binary blend of slag and Portland cement paste presented a significant increase after 5.0-7.5 hours, which is beyond the final setting time that is normally regarded as zero point for Portland cement. Here, the autogenous strain of the binary blend paste of $\mathrm{MH} 42.5$ and ASSP increased significantly within 8.5 hours based on the final setting time regarded as zero point, and the actual autogenous strain was higher considering the very early hydration of the cement and the ASSP particles.

3.2. Heat of Hydration. The heat of hydration releasing processes of samples coded A1 and S5 are presented in Figure 6 , and the characteristic values obtained by calculation are listed in Table 4. Overall, the heat of hydration releasing processes of the ASSP binary and ternary blend pastes are similar to that of cement paste and different in heat of hydration releasing intensity and process. By comparison, the binary blend paste with 15\% ASSP added reduced the heat of hydration released within 72 hours by exactly $15 \%$, which is consistent with that in the aforementioned compressive strength tested at 7 days. Within this Table $4,100 \%$ refers to the total heat of hydration released by $\mathrm{A} 0$, and $85 \%$ refers to the ratio of heat of hydration between A1 and A0. Likewise, other percentages in this table are similarly expressed. The ternary blend pastes with $5 \%$ SF and $20 \%$ ASSP reduced the heat of hydration released within 72 hours by $28 \%$, slightly exceeding its replacement.

For the binary blend paste coded A1, the first heat flow peak produced by $\mathrm{C}_{3} \mathrm{~A}$ hydration accelerated from $224.9 \mathrm{~s}$ to $276.8 \mathrm{~s}$, and its heat flow peak decreased by only $5 \%$; the second heat flow peak produced by $\mathrm{C}_{3} \mathrm{~S}$ hydration [23] accelerated from 9.45 hours to 8.91 hours, and its heat flow peak decreased by $9 \%$. For the ternary blend paste coded S5, 


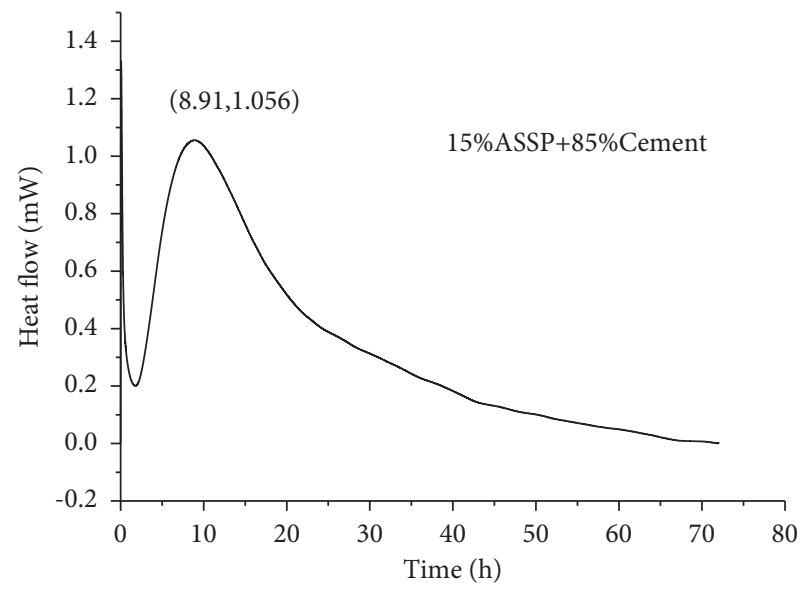

(a)

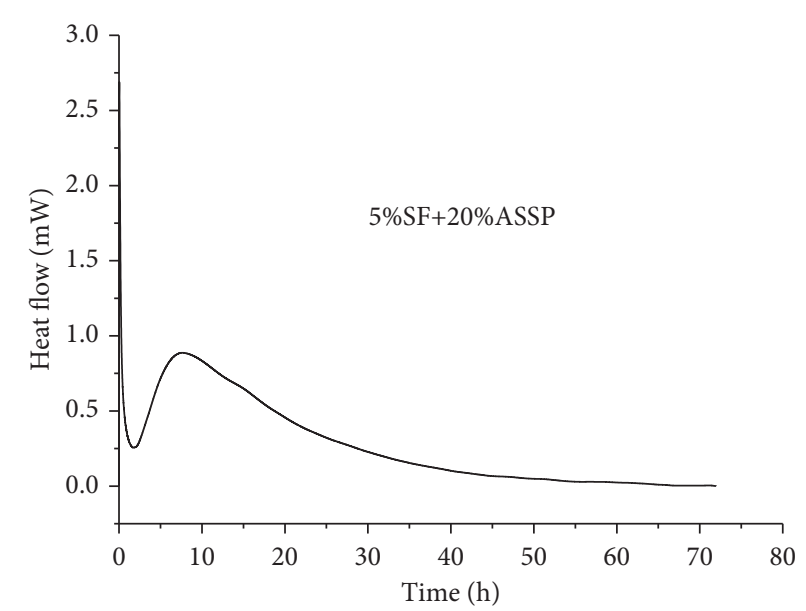

(b)

FIgURE 6: Heat of hydration curve of the binary blends paste with addition of ASSP. (a)A1 and (b)S5.

TABle 4: The characteristic value of heat flow releasing process within 72 hours.

\begin{tabular}{|c|c|c|c|c|c|}
\hline \multirow{2}{*}{ Pastes } & \multirow{2}{*}{$\begin{array}{c}\text { Heat of hydration } \\
\mathrm{kJ} / \mathrm{kg}\end{array}$} & \multicolumn{2}{|c|}{ The first heat flow peak } & \multicolumn{2}{|c|}{ The second heat flow peak } \\
\hline & & Occurring time/s & Heat flow $/ \mathrm{mW}$ & Occurring time/s & Heat flow $/ \mathrm{mW}$ \\
\hline A0 & $198.0 / 100 \%$ & 276.8 & $1.402 / 100 \%$ & 34020 & $1.155 / 100 \%$ \\
\hline A1 & $168.4 / 85 \%$ & 224.9 & $1.331 / 95 \%$ & 32076 & $1.056 / 91 \%$ \\
\hline S5 & $141.8 / 72 \%$ & 138.4 & $2.690 / 192 \%$ & 27576 & $0.887 / 77 \%$ \\
\hline
\end{tabular}

the first heat flow peak accelerated from 276.8 seconds to 138.4 seconds, and the heat flow peak increased from $1.402 \mathrm{~mW}$ to $2.690 \mathrm{~mW}$; the second heat flow peak accelerated from 9.45 hours to 7.66 hours, and the heat flow peak decreased by $23 \%$, which is slightly lower than its replacement of $25 \%$.

The incorporation of fine particles of ASSP and SF has a positive accelerating effect on the early hydration of aluminum- and silicon-phase minerals in the cement clinker $[11,13]$, and part of the ASSP and SF particles participate in the pozzolanic reaction with $\mathrm{Ca}(\mathrm{OH})_{2}$ as indicated by the gap between the replacement and reduction in heat flow peaks, whereas the total amounts of heat of hydration of the binary and ternary blend pastes within 72 hours remain lower than that of the cement paste.

3.3. SEM. The SEM patterns of the products of hydration of the binary and ternary blend pastes are presented in Figures 7-10. At the 7th day, the products of hydration produced by the binary and ternary blend pastes were similar to those of cement paste and the cotton-shaped C-S$\mathrm{H}$ and rod-like AFt deposit on surfaces of the ASSP and FA particles. The products of hydration of the binary blend pastes of P.MH 42.5 and ASSP ranged from $5 \mu \mathrm{m}$ to $10 \mu \mathrm{m}$ on the 28th day, and by the 56th day the amount of rod-like AFt increased, while the cotton-shaped C-S-H decreased.

For the ternary blend pastes of P.MH 42.5, FA, and ASSP, the structure is more condensed due to large amount of C-S-H gel formed with a low $\mathrm{CaO} / \mathrm{SiO}_{2}$ ratio as shown by the comparison of Figures $7(\mathrm{c})$ and $8(\mathrm{c})$, favorable to the strength growth and characteristic diffraction peaks of $\mathrm{SiO}_{2}$ which are discernible in the binary blend paste of P.MH 42.5 and ASSP at 56 days as illustrated in Figure 9. Unlike limestone powder pastes, no sign of $3 \mathrm{CaO} \cdot \mathrm{SiO}_{2} \cdot \mathrm{CaCO}_{3} \cdot 11 \mathrm{H}_{2} \mathrm{O}$ could be observed on the XRD pattern $[10,24]$, which is probably because limestone primarily consists of $\mathrm{CaCO}_{3}[10,14]$, whereas ASSP has $78.4 \%$ of siliceous and aluminum phases.

For the ternary blend paste of P.MH 42.5, SF, and ASSP, the hydration degree increased compared with the aforementioned pastes, as shown in Figure 10. On the 7th day, many fine fluffy and fibrous products of hydration could be seen extending outward from unhydrated particles, distributed in the cementation system and connected with each other to form a network, with sizes more than $10 \mu \mathrm{m}$. With the deepening of the hydration degree, the products of hydration on the 90th day piled up, interweaved, and interconnected to produce a dense interface. In general, the coupled addition of ASSP with FA or SF could reduce the $\mathrm{CaO} / \mathrm{SiO}_{2}$ ratio of the products of hydration and improve the structural compactness of the hydration system.

3.4. TGA. $\mathrm{Ca}(\mathrm{OH})_{2}$ is a key indicator of the hydration degree of cement-based materials [25] because it is one of the products of hydration of cement clinkers and the reactant of pozzolanic reaction with supplementary materials. Chemical combined water is present within C-S-H and AFt and could be measured by tracking the decomposing zone of C-S-H and AFt from 50 to $400^{\circ} \mathrm{C}$. 


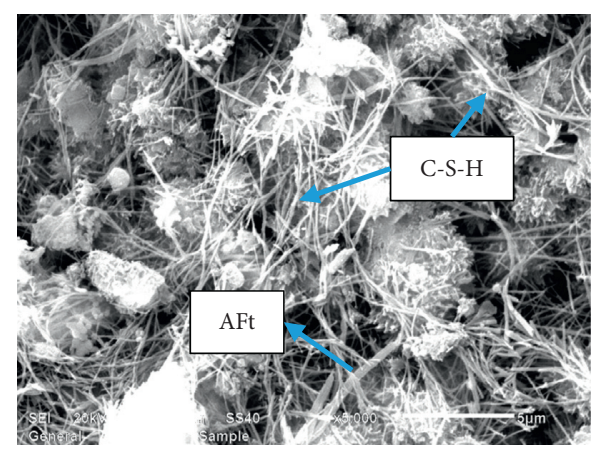

(a)

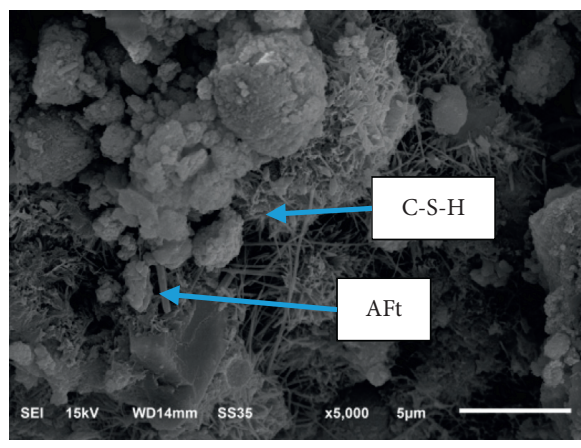

(c)

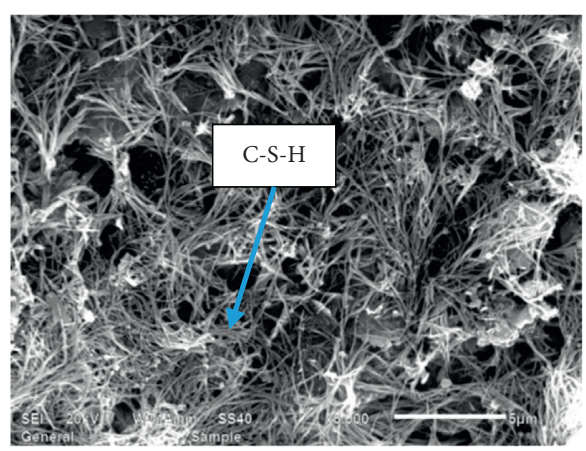

(b)

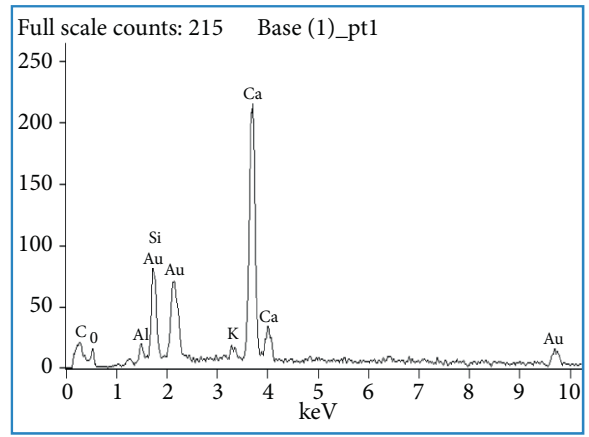

FiguRE 7: SEM/EDS pattern of sample coded A2. (a) A2-7 d (×5000), (b) A2-28 d (×5000), and (c) A2-56 d and EDS pattern.

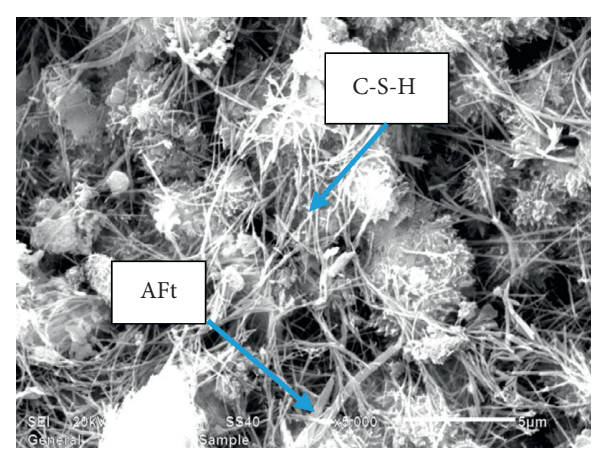

(a)

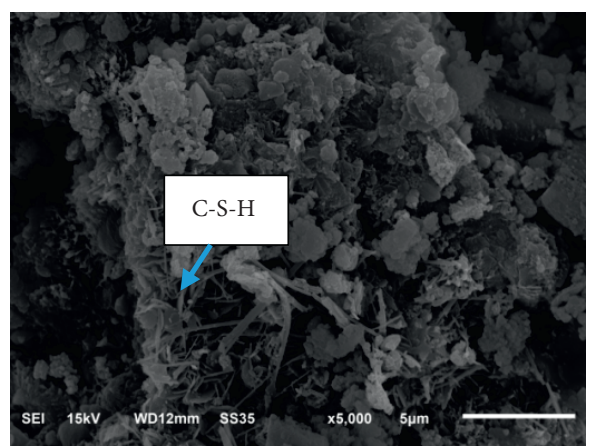

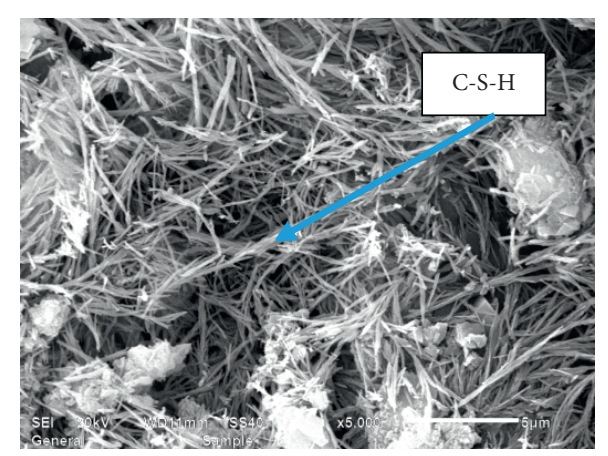

(b)

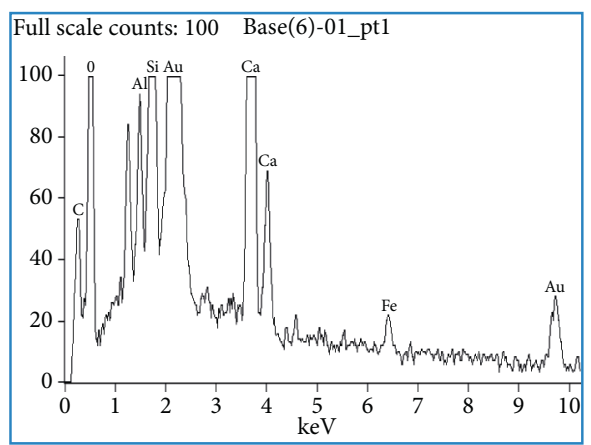

(c)

FIGURE 8: SEM/EDS pattern of ASSP-FA-cement ternary pastes of sample coded AF1. (a) AF1-7 d ( $\times 5000)$, (b) AF1-28d ( $\times 5000)$, and (c) AF1-56d (×5000). 


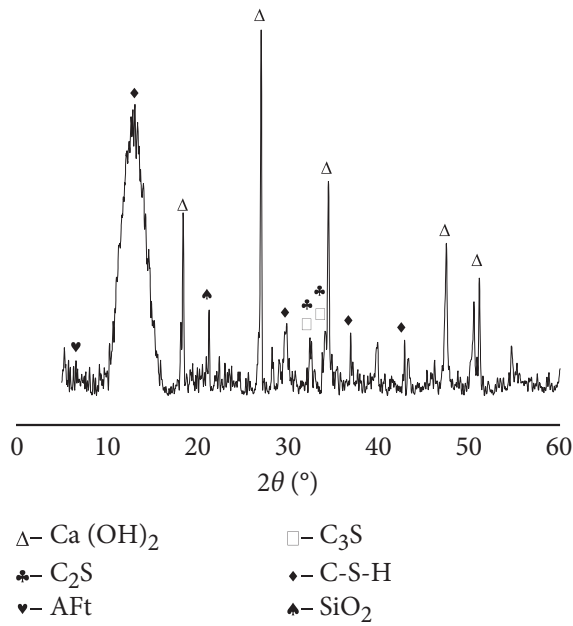

(a)

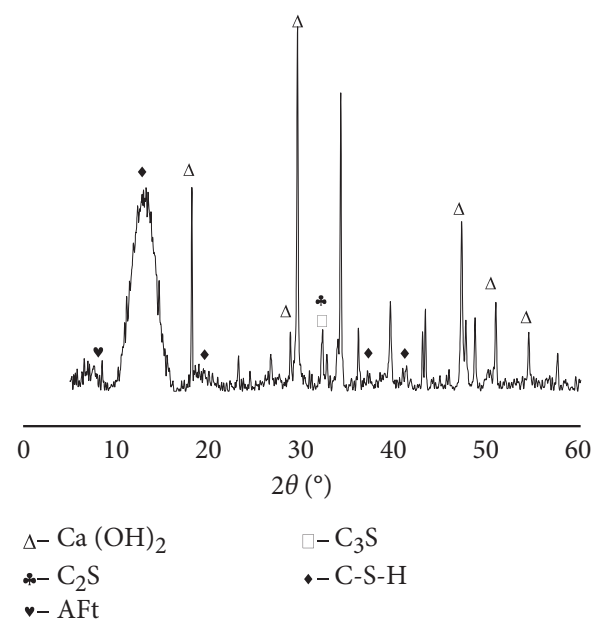

(b)

FIGURE 9: XRD pattern of ASSP binary and ternary blends pastes-56 d. (a) A2, (b) AF1.

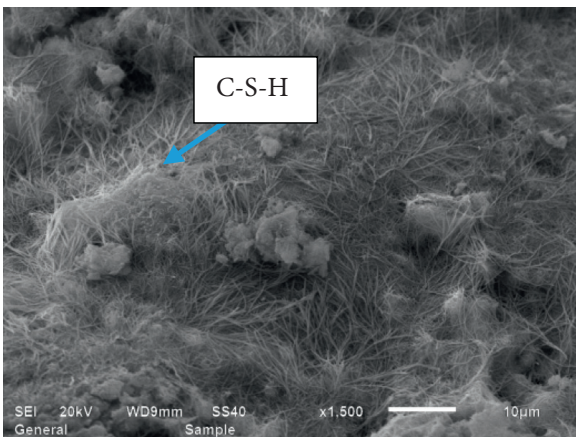

(a)

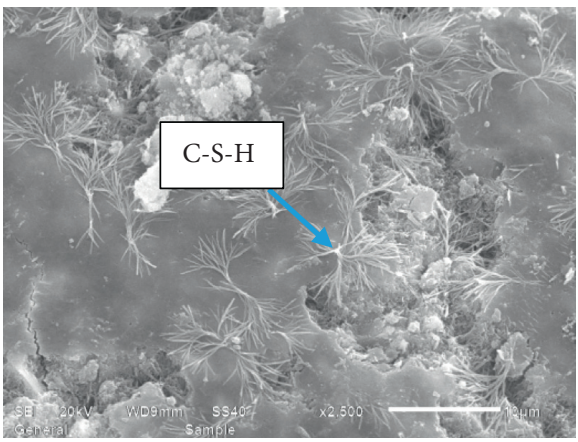

(c)

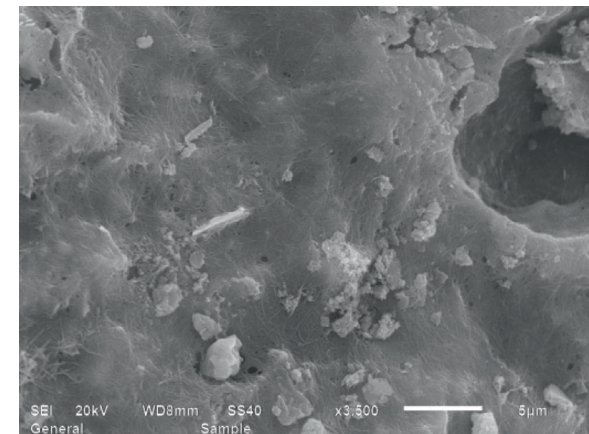

(b)

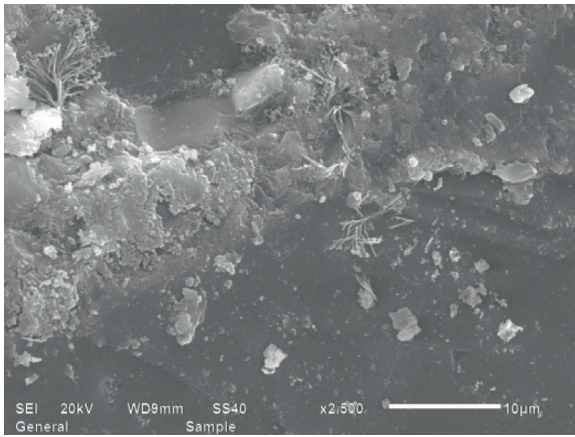

(d)

FiguRE 10: SEM pattern of ternary blends paste of sample coded S5. (a) S5-7 d (×1500), (b) S5-28 d (×3500), (c) S5-90 d (×2500), and (d) S5$180 \mathrm{~d}(\times 2500)$.

The TGA patterns of the binary and ternary blend pastes are shown in Figure 11, and the $\mathrm{Ca}(\mathrm{OH})_{2}$ content and the chemical combined water are calculated and listed in Table 5. By comparison, the content of $\mathrm{Ca}(\mathrm{OH})_{2}$ on the 7 th day produced by binary and ternary blend pastes is higher than that of the controlled cement paste, and the ternary blend paste of sample coded S5 has the highest content of $\mathrm{Ca}(\mathrm{OH})_{2}$, implying its significant acceleration effect on the hydration of cement particles at the early stage. On the 28 th and the 90th day, the content of $\mathrm{Ca}(\mathrm{OH})_{2}$ produced by binary and ternary blend pastes is lower than that of the controlled cement paste, but the difference is mitigated with age. Notably, the content of $\mathrm{Ca}(\mathrm{OH})_{2}$ has an increasing trend with age extending from the 7 th to the 90th day. During the hydration process of cement particles, $\mathrm{Ca}(\mathrm{OH})_{2}$ is released by hydration of $\mathrm{C}_{3} \mathrm{~S}$ and $\mathrm{C}_{2} \mathrm{~S}$, while it is consumed by hydration of $\mathrm{C}_{3} \mathrm{~A}$ and $\mathrm{C}_{4} \mathrm{AF}$ and by phase transformation from AFt to AFm. Here, it is assumed that by the 90th day, some 


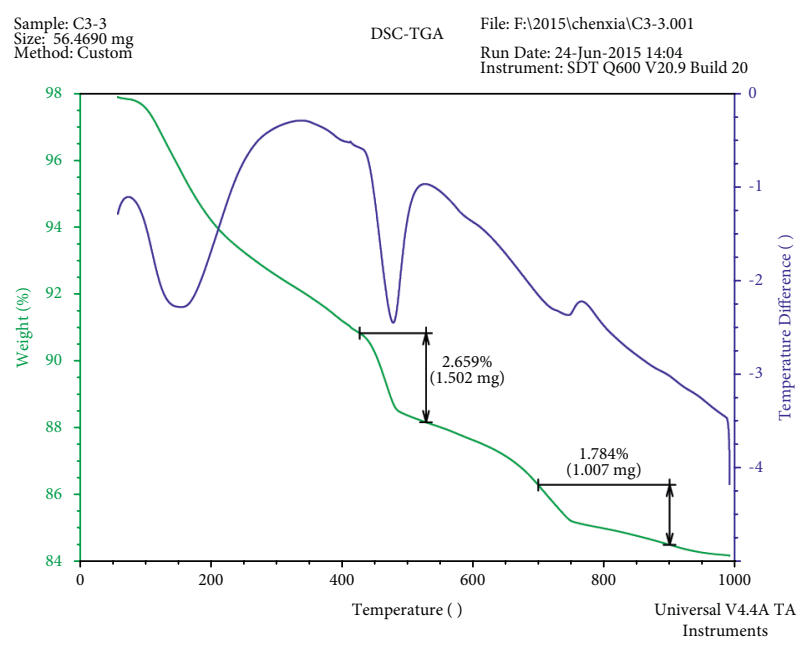

(a)

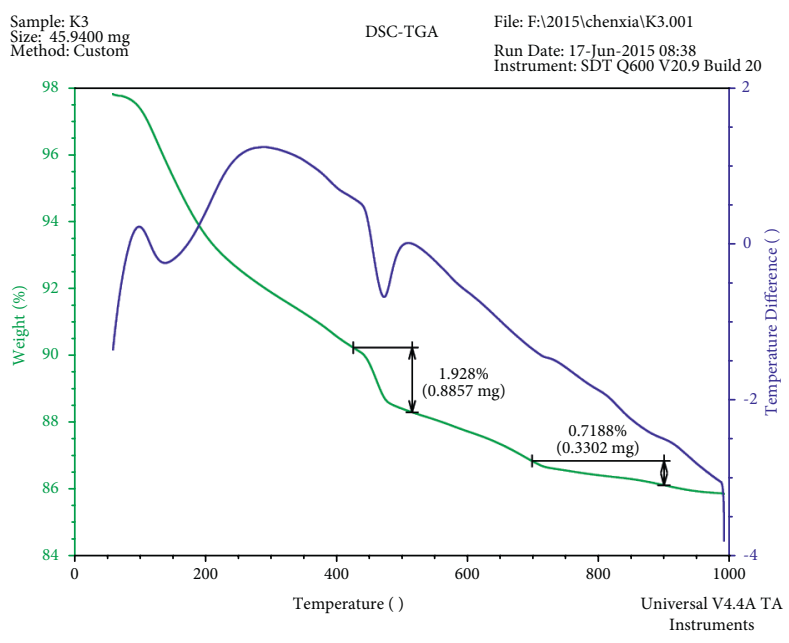

(b)

FIGURE 11: TG pattern of ASSP binary and ternary blends pastes-90 d. (a) 25\% ASSP and (b) 5\% SF + 20\% ASSP.

TAble 5: Quantitative measurement of $\mathrm{Ca}(\mathrm{OH})_{2}$ and chemical combined water (\%).

\begin{tabular}{|c|c|c|c|c|c|c|}
\hline \multirow{2}{*}{ Pastes } & \multicolumn{3}{|c|}{$\mathrm{Ca}(\mathrm{OH})_{2}$} & \multicolumn{3}{|c|}{ Chemical combined water } \\
\hline & $7 \mathrm{~d}$ & $28 \mathrm{~d}$ & $90 \mathrm{~d}$ & $7 \mathrm{~d}$ & $28 \mathrm{~d}$ & $90 \mathrm{~d}$ \\
\hline A0 & 9.65 & 13.32 & 14.74 & 14.19 & 18.35 & 21.35 \\
\hline A2 & 10.22 & 11.92 & 13.94 & 11.53 & 15.89 & 18.70 \\
\hline AF1 & 10.20 & 11.96 & 13.86 & 10.82 & 16.31 & 18.81 \\
\hline S5 & 10.81 & 12.25 & 13.79 & 13.58 & 17.56 & 19.78 \\
\hline
\end{tabular}

amounts of $\mathrm{C}_{3} \mathrm{~S}$ and $\mathrm{C}_{2} \mathrm{~S}$ particles remain present and keep stable hydration, and only part of phase transformation takes place, which results in the accumulation of more $\mathrm{Ca}(\mathrm{OH})_{2}$ in the paste.

The chemical combined water of the binary and ternary blend pastes remained lower than that of the controlled cement paste during the testing age, but the reduction rate in the chemical combined water of the individual paste was less than the replacement of the mineral admixture by the total amount of cementitious materials, suggesting that some ASSP particles were also involved in the hydration or accelerated hydration of the cement clinkers.

3.5. MIP. The porosity and pores distribution testing results of the binary and ternary blend pastes via MIP are shown in Table 6 and Figure 12. Apparently, the most probable aperture and porosity of the binary and ternary blend pastes presented a downward trend with age, and the ternary blend paste of sample coded S5 had the lowest porosity at the same testing age. The porosity of the binary blend paste of sample coded A2 decreased from $19.20 \%$ on the 7 th day to $17.83 \%$ on the 28th day, that of the ternary blend paste of sample coded AF1 decreased from $21.17 \%$ on the 3rd day to $13.04 \%$ on the 180th day, and that of the ternary blend paste of sample coded S5 decreased from $19.05 \%$ on the 7 th day to $14.61 \%$ on the 90 th day.
The proportion of pore sized between 5 and $50 \mathrm{~nm}$ showed the most significant increase with age, and the opposite trend for pore sizes ranged from $100 \mathrm{~nm}$ to $200 \mathrm{~nm}$. The total amount of pores below $50 \mathrm{~nm}$ accounted for $44.74 \%$ and $57.44 \%$, respectively, for the binary blend paste of sample coded A2 and the ternary blend paste of sample coded S5 on the 28th day. The proportion of pores which ranged from 100 to $200 \mathrm{~nm}$ for the ternary blend paste of sample coded S5 decreased significantly from the 7th day to the 28th day but decreased slightly from the 28th day to the 90th day.

Analysis indicated that the extremely fine particles of SF acted as dispersion activation nucleation points, participated in pozzolanic reaction, and played the role of micro void filling material [26]; Said et al. [27] promoted the early hydration of aluminum- and silicon-phase minerals in the cement clinker and resulted in sharp decline in the most probable aperture and porosity of the pastes. However, the products of hydration during this period primarily came from the hydration of cement clinkers and deposited nearby, featured by high porosity [28] and large size due to high alkalinity of the liquid. As the hydration deepened, SF and ASSP took part in the hydration and fast consumption of $\mathrm{Ca}(\mathrm{OH})_{2}$, which reduced the alkalinity of the liquid $[14,29]$. Furthermore, the products of hydration formed during this period featured a small size and a low $\mathrm{CaO} / \mathrm{SiO}_{2}$ ratio, greatly contributing to the refinement of pores and the growth of strength. 
TABLE 6: Porosity and pores distribution of the binary and ternary blends pastes.

\begin{tabular}{|c|c|c|c|c|c|c|c|}
\hline \multirow{2}{*}{ No. } & \multirow{2}{*}{ Pastes } & \multirow{2}{*}{ Age (d) } & \multirow{2}{*}{ Porosity (\%) } & \multicolumn{4}{|c|}{ Pores distribution (nm) } \\
\hline & & & & $<5$ & $5 \sim 50$ & $50 \sim 100$ & $100 \sim 200$ \\
\hline 1 & \multirow{2}{*}{$\mathrm{A} 2$} & 7 & 19.20 & 4.56 & 24.61 & 11.17 & 59.66 \\
\hline 2 & & 28 & 17.83 & 7.82 & 36.92 & 21.48 & 33.78 \\
\hline 3 & \multirow{3}{*}{ AF1 } & 3 & 21.17 & 2.24 & 17.12 & 8.38 & 72.26 \\
\hline 4 & & 7 & 19.20 & 4.32 & 24.64 & 10.99 & 60.05 \\
\hline 5 & & 180 & 13.04 & 8.31 & 39.77 & 9.32 & 42.60 \\
\hline 6 & \multirow{3}{*}{ S5 } & 7 & 19.05 & 5.39 & 33.79 & 11.8 & 49.02 \\
\hline 7 & & 28 & 17.58 & 9.13 & 48.31 & 13.27 & 29.29 \\
\hline 8 & & 90 & 14.61 & 11.98 & 54.22 & 4.84 & 28.96 \\
\hline
\end{tabular}

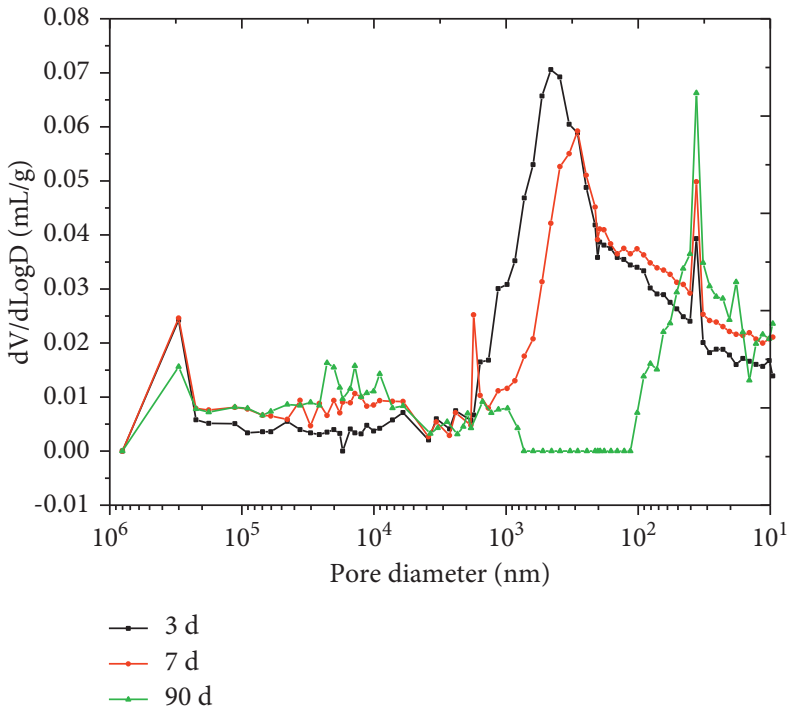

(a)

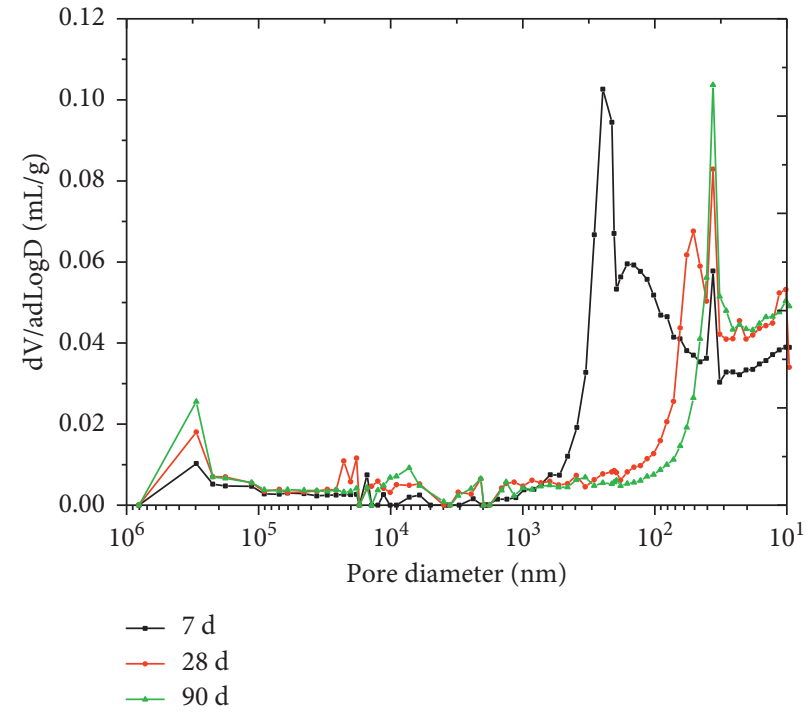

(b)

FIgURe 12: Pores distribution of ASSP ternary blends pastes by MIP. (a) AF1, (b) S5.

3.6. Relationship between Porosity and Strength. To explore the influence of the single or coupled addition of ASSP, FA, and SF on the macro performance of the binary and ternary blend pastes, the relationship between the pore structure parameters and the strength of the blends is established and illustrated in Figure 13. The fitting formulas between the strength and the pore structure parameters are shown in Table 7.

Figures 13(a) and 13(b) show that the flexural and compressive strengths of the binary and ternary blends have a significant positive correlation with the pore size less than $50 \mathrm{~nm}$ and a negative correlation with the total porosity, and the adjustments of the coefficient of determination, respectively, reach up to 0.9446 and 0.9564 . Unlike the total porosity, the flexural and compressive strengths of the binary and ternary blends present an apparent increasing trend with the development of the pore size less than $50 \mathrm{~nm}$, suggesting the greater contribution of pore size refinement to strength development than porosity decrease.

The porosity of the binary blend paste of sample coded A2 is approximate to that of the ternary blend paste of sample coded S5 on the 28th day, which are $17.83 \%$ and $17.58 \%$, respectively, but the corresponding pore sizes less than $50 \mathrm{~nm}$ are $44.74 \%$ and $57.44 \%$, respectively, indicating why the latter has higher compressive and flexural strengths at the same age. Likewise, although the ternary blend paste of sample coded AF1 has a porosity of $13.04 \%$ on the 180 th day, slightly lower than that of the ternary blend paste of sample coded S5 which has a porosity of $14.61 \%$ on the 90th day, big gap is present between the corresponding compressive strengths which are $47.0 \mathrm{MPa}$ and $55.1 \mathrm{MPa}$, respectively, and the reason is attributed to the difference in the corresponding pore sizes less than $50 \mathrm{~nm}$, which are $48.08 \%$ and $66.20 \%$, respectively.

As illustrated in Figure 2, ASSP has 38.1\% particles below $5 \mu \mathrm{m}$ and $72.8 \%$ particles below $24 \mu \mathrm{m}$, while SF has $79.3 \%$ particles below $5 \mu \mathrm{m}$, and these fine particles are introduced in the binary and ternary blends to compact the voids among multiple components step by step and decrease porosity [30] for improved compaction. The finer particles of ASSP, FA, and SF also act as dispersion activation nucleation points and promote the early hydration of aluminum- and siliconphase minerals in the cement clinker and consequently contribute to early strength growth. Furthermore, the very fine particles of ASSP with low surface activation energy are involved in the pozzolanic reaction with $\mathrm{Ca}(\mathrm{OH})_{2}$. Thus, the 


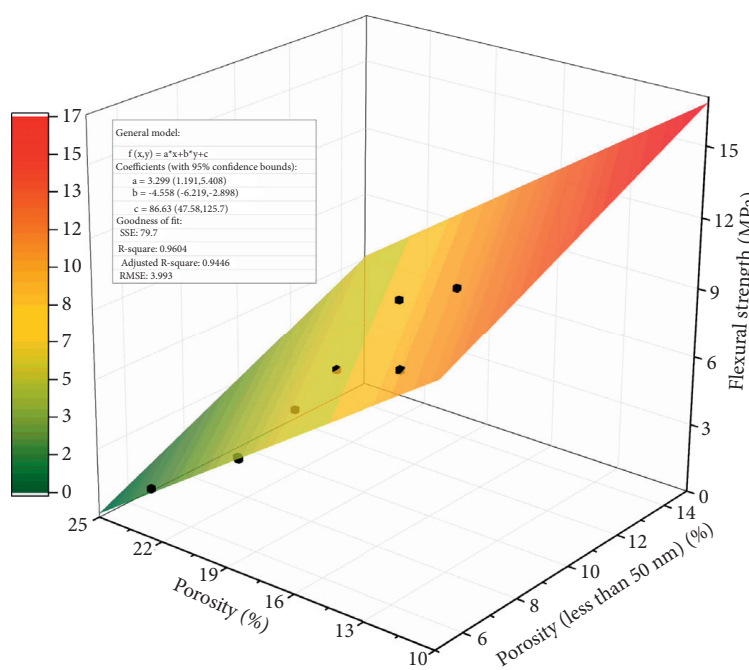

(a)

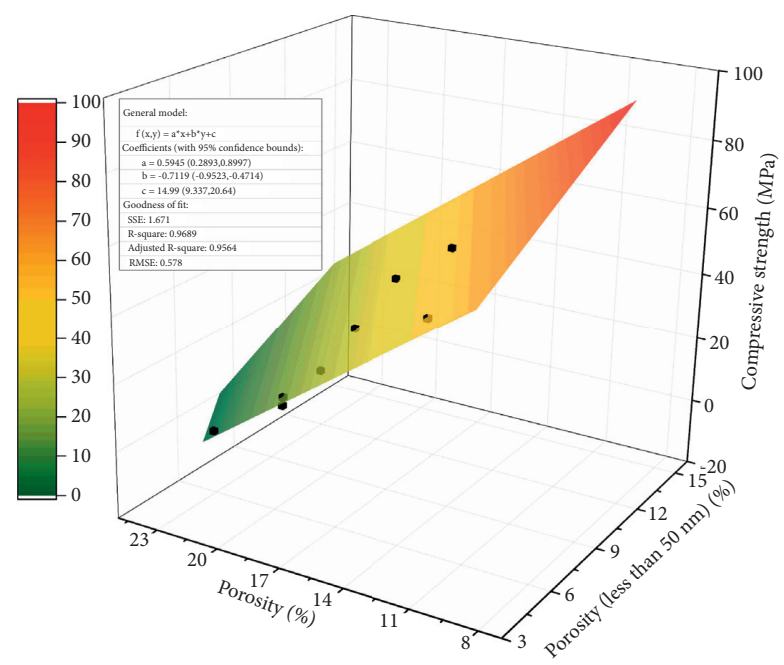

(b)

FIgURE 13: Relationship between strength and pore structure parameters of the binary and ternary blends. (a) Compressive strength and porosity parameters. (b) Flexural strength and porosity parameters.

TABLE 7: The fitting formulas between strength and pore structure parameters.

\begin{tabular}{lcc}
\hline Strength & Fitting formula & Adj. $R$-square \\
\hline Compressive strength & $f_{1}=14.99+0.5945 x_{1}-0.7119 x_{2}$ & 0.9564 \\
Flexural strength & $f_{2}=86.63+3.299 x_{1}-4.558 x_{2}$ & 0.9446 \\
\hline
\end{tabular}

TABLE 8: Price of raw materials for use in concrete.

\begin{tabular}{lcccccccc}
\hline Raw materials & P.MH 42.5 & ASSP & FA & SF & Fine aggregate & Coarse aggregate & Water reducer agent & Air-entraining agent \\
\hline Price (U.S. dollar/ton) & 92.8 & 46.4 & 116.0 & 170.2 & 6.2 & 4.6 & 928.4 & 1547.4 \\
\hline
\end{tabular}

TABLE 9: Mix proportion and unit price of pump concrete with different binary and ternary blends.

\begin{tabular}{lccccccc}
\hline $\begin{array}{l}\text { Cementitious } \\
\text { materials }\end{array}$ & $\begin{array}{c}\text { W/ } \\
\text { B }\end{array}$ & $\begin{array}{c}\text { Water } \\
\left(\mathrm{kg} / \mathrm{m}^{3}\right)\end{array}$ & $\begin{array}{c}\text { Fine aggregate } \\
\left(\mathrm{kg} / \mathrm{m}^{3}\right)\end{array}$ & $\begin{array}{c}\text { Coarse aggregate } \\
\left(\mathrm{kg} / \mathrm{m}^{3}\right)\end{array}$ & $\begin{array}{c}\text { Water reducer } \\
\text { agent }\left(\mathrm{kg} / \mathrm{m}^{3}\right)\end{array}$ & $\begin{array}{c}\text { Air-entraining } \\
\text { agent }\left(\mathrm{kg} / \mathrm{m}^{3}\right)\end{array}$ & $\begin{array}{c}\text { Unit price (U.S. } \\
\left.\text { dollars } / \mathrm{m}^{3}\right)\end{array}$ \\
\hline 15\% ASSP + 15\% & 0.39 & 148 & 729 & 1116 & 2.58 & 0.034 & 46.0 \\
FA & 0.42 & 142 & 807 & 1090 & 1.93 & 0.051 & 45.3 \\
$25 \%$ FA & 0.44 & 152 & 740 & 1130 & 3.38 & 0.031 & 42.4 \\
$5 \%$ SF + 25\% ASSP & 0.49 & & \\
\hline
\end{tabular}

C-S-H gel with a low $\mathrm{CaO} / \mathrm{SiO}_{2}$ ratio is produced as shown in Figure 6, and large amounts of products of hydration would improve the compaction of pastes and reduce porosity, resulting in the early flexural and compressive strength growth of the ASSP binary and ternary blend pastes.

In Table $7, f_{1}$ refers to the compressive strength of the binary and ternary blends, $\mathrm{MPa} ; f_{2}$ refers to the flexural strength of the binary and ternary blends, $\mathrm{MPa} ; x_{1}$ refers to the porosity sized less than $50 \mathrm{~nm}$ of the binary and ternary blends, $\% ; x_{2}$ refers to the total porosity of the binary and ternary blends, $\%$.

3.7. Economic Effects Evaluation. The unit prices of the pumping concrete produced by three kinds of binary and ternary blends are compared, and the cost is calculated based on the raw materials used as listed in Table 8. The unit price of the pump concrete produced by different binary and ternary blends is listed in Table 9.

To produce a pumping concrete with compressive strength of $25 \mathrm{MPa}$ on the 28th day, the unit price is 46.0 dollars $/ \mathrm{m}^{3}$ for concrete with the coupled addition of ASSP, 45.3 dollars $/ \mathrm{m}^{3}$ for concrete with FA added only, and 42.4 dollars $/ \mathrm{m}^{3}$ for concrete with the coupled addition of SF and ASSP. In general, the hybrid ASSP and SF showed the most prominent economic effect and the most optimal mechanical and deformation properties; the coupled addition of $25 \%$ ASSP and 5\% SF achieved the lowest unit price of 42.4 dollars $/ \mathrm{m}^{3}$, and this combination was finally selected as the optimal mineral admixture for use in the Lianghekou hydropower station dam construction. By comparison, great advantage in economic effect is clear for use of alkali-active sand slate aggregate as mineral admixture by second process, 
and this provides a good inspiration for those hydropower station construction that has to use local alkali-active rock.

\section{Conclusions}

Based on investigations on the macro performance and micro structure of the binary and ternary blends with incorporation of ASSP as mineral admixture and economic effect evaluation, it is safe to reach the conclusion as follows:

(1) The ternary blends of P.MH 42.5, 5-8 wt.\% SF, and 15-20 wt.\% ASSP have the optimal compressive and flexural strength and the incorporation of ASSP is able to improve ductility of mortar over 90-180 days.

(2) ASSP particle participates in hydration at early age, accelerates the hydration of $\mathrm{C}_{3} \mathrm{~A}$ and $\mathrm{C}_{3} \mathrm{~S}$ within 8.91 hours, and mitigates autogenous strain of pastes in case of dosage less than 25 wt.\%.

(3) The coupled addition of ASSP with FA or SF is favorable to reduce $\mathrm{CaO} / \mathrm{SiO}_{2}$ ratio of $\mathrm{C}-\mathrm{S}-\mathrm{H}$ and improve the compactness.

(4) Both the compressive and flexural strengths have a positive correlation with porosity size less than $50 \mathrm{~nm}$, yet they have a negative correlation with the total porosity.

(5) The hybrid of ASSP and SF has justified itself as a good alternative as mineral admixture and has been successfully implemented on Lianghekou hydropower station due to great performance and prominent economic effect.

(6) A new approach has been explored with regard to recycling and application of alkali-active rock and it could be of great significance to environment-friendly and greenery hydraulic projects construction.

\section{Data Availability}

The data used to support the findings of this study are included within the article.

\section{Conflicts of Interest}

The authors declare that they have no conflicts of interest.

\section{Acknowledgments}

The authors owe great gratitude to full support of NSFC under Grant Nos. 51979011 and U2040222 and China Central Non-Profit Scientific Research Program under Grant Nos. CKSF2021437 and CKSF2021483.

\section{References}

[1] E. Özbay, M. Erdemir, and H. İbrahim Durmuş, "Utilization and efficiency of ground granulated blast furnace slag on concrete properties-a review," Construction and Building Materials, vol. 105, pp. 423-434, 2016.

[2] Y.-J. Kwon, "A study on the alkali-aggregate reaction in highstrength concrete with particular respect to the ground granulated blast-furnace slag effect," Cement and Concrete Research, vol. 35, no. 7, pp. 1305-1313, 2005.

[3] H. Yang, P. Li, and M. Rao, "Long term investigation and inhibition on alkali-aggregates reaction of Three Gorges Dam concrete," Construction and Building Materials, vol. 151, no. 151, pp. 673-681, 2017.

[4] R. B. Figueira, R. Sousa, L. Coelho et al., "Alkali-silica reaction in concrete: mechanisms, mitigation and test methods," Construction and Building Materials, vol. 222, pp. 903-931, 2019.

[5] F. L. Costa, A. S. Torres, and R. A. Neves, "Analysis of concrete structures deteriorated by alkali-aggregate reaction: case study," Journal of Building Pathology and Rehabilitation, vol. 13, no. 1, 2016.

[6] G. Li and Q. Zhou, "Engineering measures for inhibiting concrete alkali-aggregate response during construction of high arch dam of Jinping I Hydropower Station," Water Resources and Hydropower Engineering, vol. 1, pp. 45-49, 2013.

[7] B. Szostak and G. L. Golewski, "Effect of nano admixture of $\mathrm{CSH}$ on selected strength parameters of concrete including fly ash," IOP Conference Series: Materials Science and Engineering, vol. 416, 2018.

[8] B. Szostak and G. L. Golewski, "Improvement of strength parameters of cement matrix with the addition of siliceous fly ash by using nanometric C-S-H seeds," Energies, vol. 13, no. 24, pp. 1-15, 2020.

[9] R. Cabiscol, H. Shi, I. Wünsch et al., "Effect of particle size on powder compaction and tablet strength using limestone," Advanced Powder Technology, vol. 31, no. 3, pp. 1280-1289, 2020.

[10] S. Liu and P. Yan, "Hydration properties of limestone powder in complex binding material," Journal of the Chinese Ceramic Society, vol. 77, no. 1, pp. 69-72, 2008.

[11] D. Wang, C. Shi, N. Farzadnia, Z. Shi, H. Jia, and Z. Ou, “A review on use of limestone powder in cement-based materials: Mechanism, hydration and microstructures," Construction and Building Materials, vol. 181, pp. 659-672, 2018.

[12] H. Wang, D. Wu, and Z. Mei, "Effect of fly ash and limestone powder on inhibiting alkali aggregate reaction of concrete," Construction and Building Materials, vol. 210, no. 20, pp. 620-626, 2019.

[13] L. Hu and Z. He, "A fresh perspective on effect of metakaolin and limestone powder on sulfate resistance of cement-based materials," Construction and Building Materials, vol. 262, 2020.

[14] J. Ma, Z. Yu, C. Xin, H. Shi, and X. Shen, "Effects of limestone powder on the hydration and microstructure development of calcium sulphoaluminate cement under long-term curing," Construction and Building Materials, vol. 199, pp. 688-695, 2019.

[15] A. Tolentino Souza, T. Ferreira Barbosa, A. R. Lucas, and S. White Jose dos, "Effect of limestone powder substitution on mechanical properties and durability of slender precast components of structural mortar," Journal of Materials Research and Technology, vol. 9, no. 1, pp. 847-856, 2020.

[16] B. Liguori, F. Iucolano, B. de Gennaro, M. Marroccoli, and D. Caputo, "Zeolitized tuff in environmental friendly production of cementitious material: chemical and mechanical characterization," Construction and Building Materials, vol. 99, pp. 272-278, 2015.

[17] R. Vigil de la Villa, R. Fernández, R. García, E. Villar-Cociña, and M. Frías, "Pozzolanic activity and alkaline reactivity of a 
mordenite-rich tuff," Microporous and Mesoporous Materials, vol. 126, pp. 125-132, 2009.

[18] A. G. Turkmenoglu and A. Tankut, "Use of tuffs from central Turkey as admixture in pozzolanic cements Assessment of their petrographical properties," Cement and Concrete Research, vol. 32, pp. 629-637, 2002.

[19] L. Xiang, S. Yan, and J. Li, "Compressive strength development of complex binder containing tuff powder," Journal of Building Materials, vol. 20, pp. 435-438, 2017.

[20] L. Xiang, L. Zhengping, and H. Xian, "Microstructural charateristics of composite binders containing fly ash and (or) Tuff powder," Journal of Yangtze River Scientific Research Institute, vol. 35, pp. 115-119, 2018.

[21] Z. He, L. Hu, Y. Li, J. Hu, and Y. Shao, "Use of sandstone powder as a mineral additive for concrete," Construction and Building Materials, vol. 186, pp. 276-286, 2018.

[22] Y. Ma, X. Yang, J. Hu, Z. Zhang, and H. Wang, "Accurate determination of the "time-zero" of autogenous shrinkage in alkali-activated fly ash/slag system," Composites Part B: Engineering, vol. 177, Article ID 107367, 2019.

[23] X. Chen, H. Yang, and J. Zhang, "Hydration characteristics of composite pastes with incorporation of phosphorus slag powder," Journal of Building Materials, vol. 19, no. 4, pp. 619-624, 2016.

[24] M. Gyu Don, S. Oh, S. Hwa Jung, and Y. Cheol Choi, "Effects of the fineness of limestone powder and cement on the hydration and strength development of PLC concrete," Construction and Building Materials, vol. 135, pp. 129-136, 2017.

[25] X. Chen, K. Fang, and H. Yang, "Hydration kinetics of phosphorus slag-cement paste," Journal of Wuhan University of Technology-Materials Science Edition, vol. 26, no. 1, pp. 141-146, 2011.

[26] J. F. Burroughs, J. Shannon, T. S. Rushing, K. Yi, Q. B. Gutierrez, and D. W. Harrelson, "Potential of finely ground limestone powder to benefit ultra-high performance concrete mixtures," Construction and Building Materials, vol. 141, pp. 335-342, 2017.

[27] H. Siad, A. Ahmed, K. Ozlem Kasap et al., "Influence of limestone powder on mechanical, physical and self-healing behavior of engineered cementitious composites," Construction and Building Materials, vol. 99, pp. 1-10, 2015.

[28] C. Li, L. Jiang, N. Xu, and S. Jiang, "Pore structure and permeability of concrete with high volume of limestone powder addition," Powder Technology, vol. 33, pp. 416-424, 2018.

[29] M. H. Samarakoon, P. G. Ranjith, T. D. Rathnaweera, and M. S. A. Perera, "Recent advances in alkaline cement binders: a review," Journal of Cleaner Production, vol. 227, pp. 70-87, 2019.

[30] B. Yin, T. Kang, J. Kang, Y. Chen, L. Wu, and M. Du, "Investigation of the hydration kinetics and microstructure formation mechanism of fresh fly ash cemented filling materials based on hydration heat and volume resistivity characteristics," Applied Clay Science, vol. 166, pp. 146-158, 2018. 